\title{
INFLUENCE OF WELL LOCATION ON DRAWDOWN IN AREA SURROUNDED BY VERTICAL CUTOFF WALLS
}

\author{
D. R. Mohamed ${ }^{1}$, M. M. Shahien ${ }^{2}$, H. H. Hafez ${ }^{3}$ \\ ${ }^{1}$ Cairo University/Hamza Associates, Egypt. \\ E-mail: daliaa_ragab@yahoo.com \\ 2 Tanta University, Tanta, Egypt. \\ E-mail: mshahien@hamzaconsult.org \\ ${ }^{3}$ Cairo University, Giza, Egypt. \\ E-mail: hisham.hafez@egec-xprt.com
}

\begin{abstract}
Dewatering systems with vertical partially penetrating cutoff walls are usually used in the case of deep excavation for side support system and further increases the efficiency of the groundwater control system. In this study a parametric analysis was carried out using the finite difference software VISUAL MODFLOW4.2® to study the effect of placing a deep well at different locations inside the excavated area surrounded by impervious wall on drawdown results. The dewatering system under consideration consists of a single partially penetrating deep well having a penetration depth (lw) and well yield (Q). The well is located at variable distances from the corner (the origin of $\mathrm{X}$ and $\mathrm{Y}$ axes) inside the excavated area surrounded by an impervious wall. The vertical impervious wall has a depth (lc), and the excavated area (A) surrounded with impervious wall is square and having a width (W). The aquifer is unconfined with a depth $(\mathrm{H})$ and is underlain by an impervious layer. The aquifer consists of an extended layer of fine to medium sand having permeability $(\mathrm{k})$. The soil is assumed to be homogenous and isotropic.
\end{abstract}

Keywords: Dewatering, Single partially penetrating deep well, Well location, Impervious walls, Unconfined aquifer

\section{Introduction}

The presence of groundwater in a site may have impact on the construction processes involved during the course of project construction, especially those projects that involve deep excavations. Deep excavations, especially in urban areas, require the construction of supported walls all around the site perimeter to ensure the stability of the excavation. In most of cases, the constructed walls are relatively impervious. Depending on the ground and site conditions, the walls are not penetrating all the way down through to the bottom of the aquifer and thus the walls are partially penetrating walls. The presence of ground water necessitates the lowering of the groundwater to levels below the bottom of the excavation to ensure working in dry. This paper focuses on dewatering systems that consist of deep wells inside square areas enclosed by impervious walls partially penetrating unconfined aquifers. The wells are partially penetrating the aquifer, as well. There are many factors or parameters that are related to the configurations of the components of the system that may influence the drawdown of a well in such dewatering system. This paper is a part of a comprehensive study that aims to development of a simple method for estimating the drawdown of dewatering system of the described configuration. In order to achieve such a major goal, a 3D finite difference model is developed for the problem in hand. A comprehensive parametric analysis was then carried out to investigate the influence of all the parameters on the drawdown of a deep well in such dewatering system. This paper describes the problem, the model, the parametric analysis including the involved parameters. The paper, then, focuses on the influence of well penetration depth (lw) related to cutoff wall penetration (lc), and the effect of cutoff walls penetration depth related to the unconfined aquifer depth $(\mathrm{H})$ on the drawdown of a single well. 


\section{Dewatering System Model}

The dewatering system model is described in plan and in cross section in Figures (1) and (2), respectively. The dewatering system under consideration consists of a single partially penetrating deep well having a penetration depth of lw and well yields of Q. The well is located inside a construction pit with a square shape that is $\mathrm{W}$ in width. The construction pit is surrounded by impervious walls from all sides. The walls have equal penetration depth of lc. A quadratic coordinate system can be considered with origin located at one the corners of the construction pit. The $\mathrm{x}$ and $\mathrm{y}$ axes of the coordinate system is as shown in Figure (1). The well is located at X and Y distances from the origin of the coordinate system in Figure (1). The well is located at any radial distance D between well center and wall edge. The distance between well center to any point where required to measure drawdown within the construction pit along any radial pass around the well is distance $r$ (Figure 2).

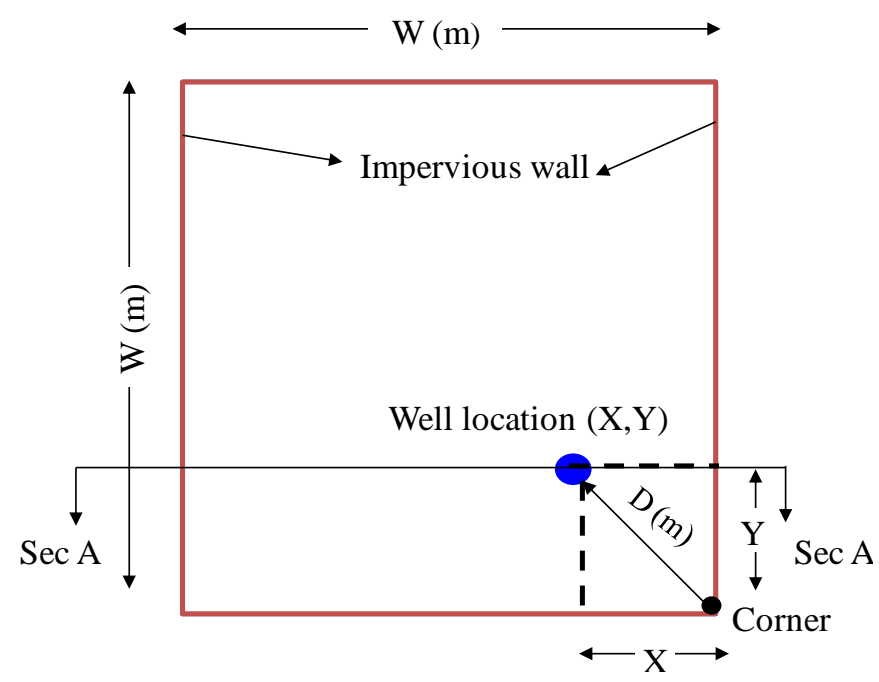

Figure 1. Plan of model area

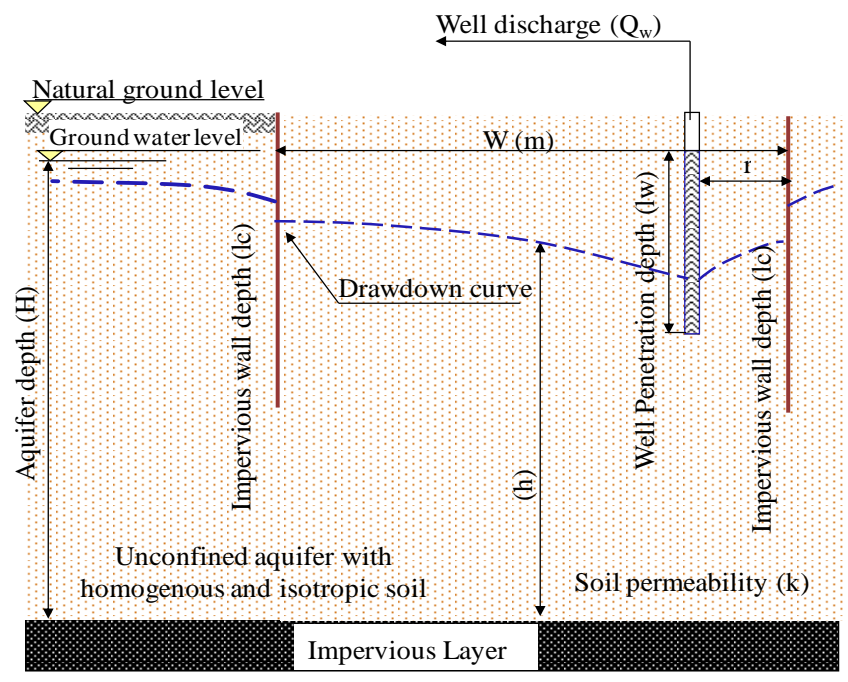

Figure 2. Section A-A 


\section{Ground Conditions}

The ground condition of the model is a continuous homogeneous isotropic fine to medium sand layer with coefficient of permeability of $\mathrm{k}$. The ground water level exists at $3.0 \mathrm{~m}$ below ground surface. The sand layer constitutes an unconfined aquifer with a depth of $\mathrm{H}$ from the ground water level. The aquifer is underlain by an impervious layer.

\section{Numerical Modeling}

MODFLOW is a three-dimensional groundwater flow model developed by McDonald and Harbaugh (1988) and Harbaugh et al. (2000). It simulates the groundwater flow using a block centered finite-difference approach for solving groundwater flow equations. It can simulate aquifer layers as confined, unconfined, or changing from confined to unconfined. Stresses from external sources such as wells, recharge, leakage from drains and riverbeds, and flow from flow-controlled or head controlled boundaries can be simulated individually or in combination through the modular structure of the model. The pumping well is represented using the well package (WELL) supported in VISUAL MODFLOW4.2®. The pumping rate and levels of the top and bottom elevations of the well screen are assigned through WELL. The vertical cutoff is represented using the horizontal flow barrier package (HFB), through which the cutoff penetration depth and the hydraulic characteristics of the barrier are assigned.

\section{Parametric Study}

A comprehensive parametric study is carried out using VISUAL MODFLOW software. The parametric study considered the variables shown in Table (1). Over 550 computer runs were carried out in this study. In order to study the influence of well location on drawdown inside square area surrounded by impervious partially penetrating walls, the results of drawdown computed from visual Modflow in different directions from well center to wall edge (d1, d2, d3 , d4, d5, d6, d7 and d8) as shown in Figure 3 are considered where;
d1, d5
: Drawdown in y-axis direction
d3, d7
: Drawdown in $\mathrm{x}$-axis direction
$\mathrm{d} 2, \mathrm{~d} 4$
: Drawdown in directions making an angle of $45^{\circ}$ with $+v e x$-axis
$\mathrm{d} 6, \mathrm{~d} 8$
: Drawdown in directions making an angle of $45^{\circ}$ with - ve $\mathrm{x}$-axis

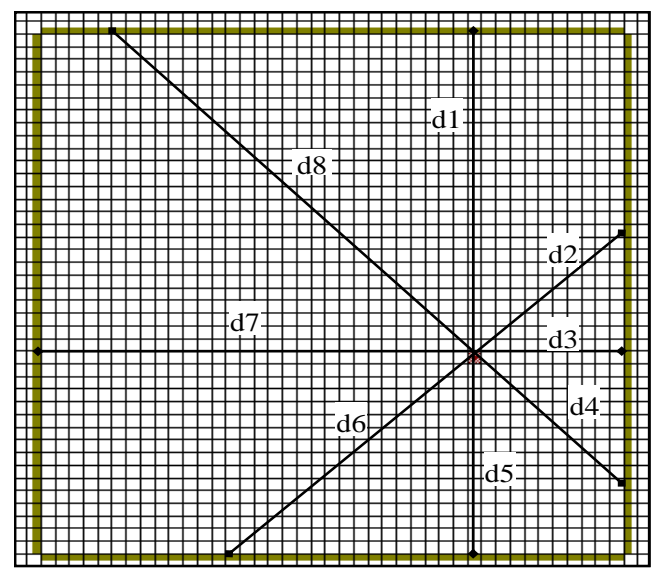

Figure 3.Different directions for predicted drawdown 
Table 1. Variables Considered In Parametric Study

\begin{tabular}{|c|c|}
\hline \multicolumn{2}{|c|}{ Variables Considered in Parametric Study } \\
\hline Variable & Range of values used \\
\hline $\begin{array}{c}\text { Coefficient of permeability } \\
(\mathrm{m} / \mathrm{sec})\end{array}$ & $0.5,1,2.5,5.0,8.0 \times 10^{-4}$ \\
\hline Well pumping rate Q $\left(\mathrm{m}^{3} / \mathrm{h}\right)$ & $30,45,60$ and 90 \\
\hline $\begin{array}{c}\text { Well penetration depth/ } \\
\text { Impervious wall penetration } \\
\text { depth lw/lc (dimensionless) }\end{array}$ & $0.75,1.00$ and 1.25 \\
\hline $\begin{array}{c}\text { Depth of aquifer H (m) } \\
\text { Area surrounded by square } \\
\text { impervious wall WxW, W (m) }\end{array}$ & $21,31,41,71$ and 100 \\
\hline $\begin{array}{c}\text { Location of well (distance from } \\
\text { well center to closest } \\
\text { impervious wall edge in } \\
\text { direction of } \mathrm{x}, \mathrm{y} \text { axis), } \mathrm{X}, \mathrm{Y} \\
(\mathrm{m})\end{array}$ & $\begin{array}{c}\text { Several values covering } \\
\text { entire area from } \\
0\end{array}$ \\
\hline
\end{tabular}

\section{Results of Parametric Analysis In Relation to Well Location 6.1 Typical result of draw down curve}

Figure 4 shows typical result of the parametric analysis that show drawdown curves along a certain direction starting from outside the impervious wall, across the wall, to well center, to the other wall in the direction $\mathrm{d} 1$, across the other wall and beyond the wall outside the construction pit. The drawdown curve when crossing the impervious wall shows a sudden change as stated by (Discrol, 1986, Freeze et al., 1979, Powers, 1992, Preene, et al., 2000, and Abdel Haleem, 2006).

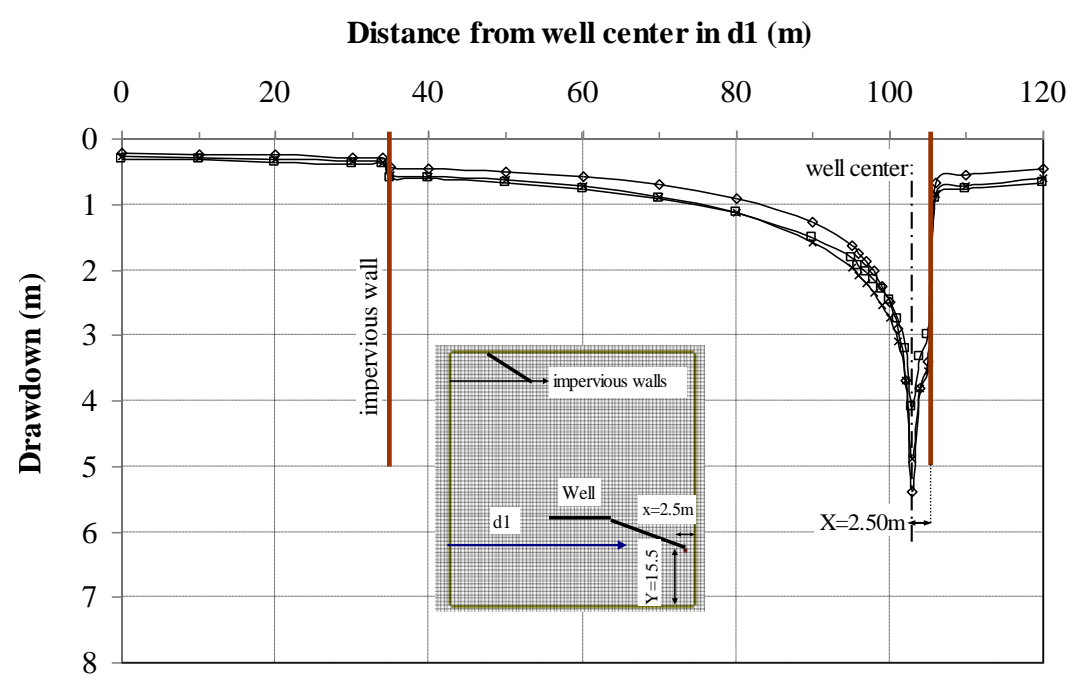

Figure 4 Typical Drawdown curve along different distances from well center 


\subsection{Draw down curves along horizontal distances from well center at different well locations}

Figures 5, 6, 7 and 8 show results of drawdown curves for wells in construction pits with sizes $21 \mathrm{mx} 21 \mathrm{~m}, 31 \mathrm{~m} \times 31 \mathrm{~m}, 41 \mathrm{mx} 41 \mathrm{~m}$ and $71 \mathrm{~m} \times 71 \mathrm{~m}$, respectively. In each figure, the drawdowns of two cases of individual wells of different locations are presented along the directions of $\mathrm{d} 3$ and $\mathrm{d} 7$ (Figure 3). One of the two locations is near the impervious boundary at $\mathrm{x}=\mathrm{y}=2.5 \mathrm{~m}$ from the corner of the construction pit, while the second location is at the center of the construction pit.

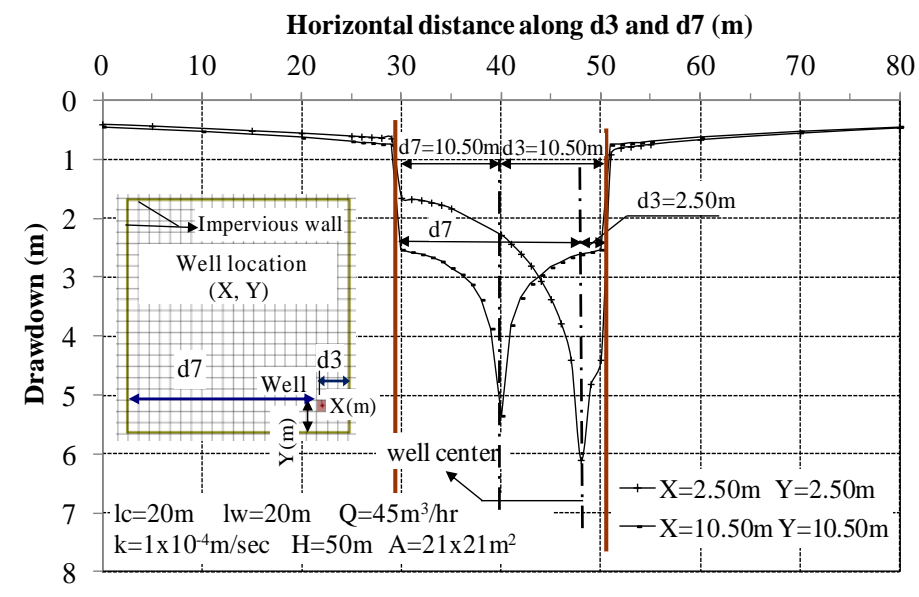

Figure 5. Drawdown curve for different well location in A $21 \times 21 \mathrm{~m}^{2}$

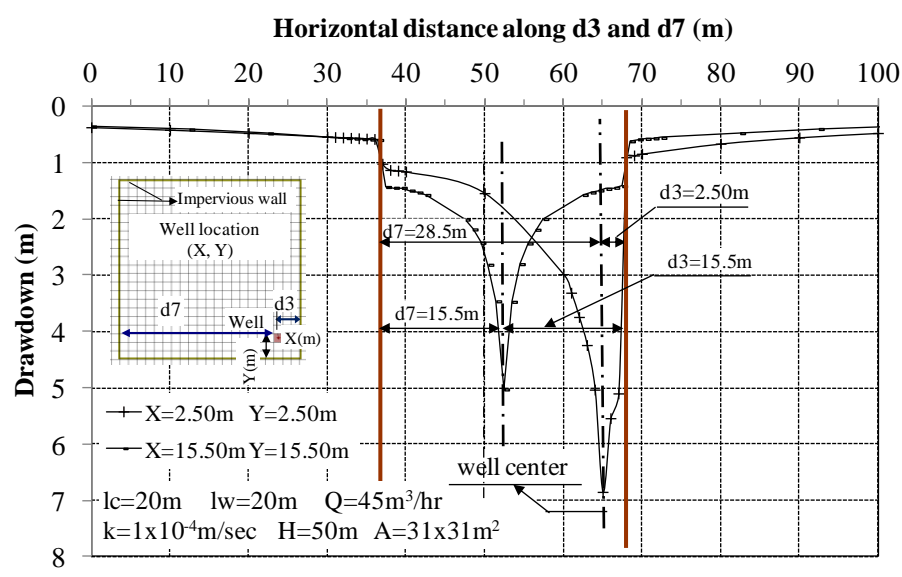

Figure 6. Drawdown curve for different well location in A $31 \times 31 \mathrm{~m}^{2}$

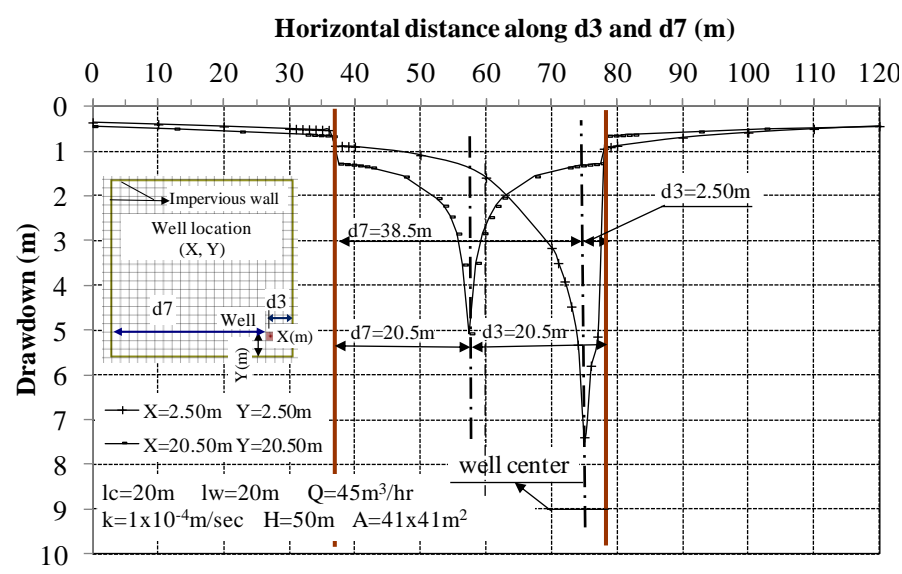


Figure 7. Drawdown curve for different well location in A $41 \times 41 \mathrm{~m}^{2}$

Horizontal distance along $\mathrm{d} 3$ and $\mathrm{d} 7$ (m)

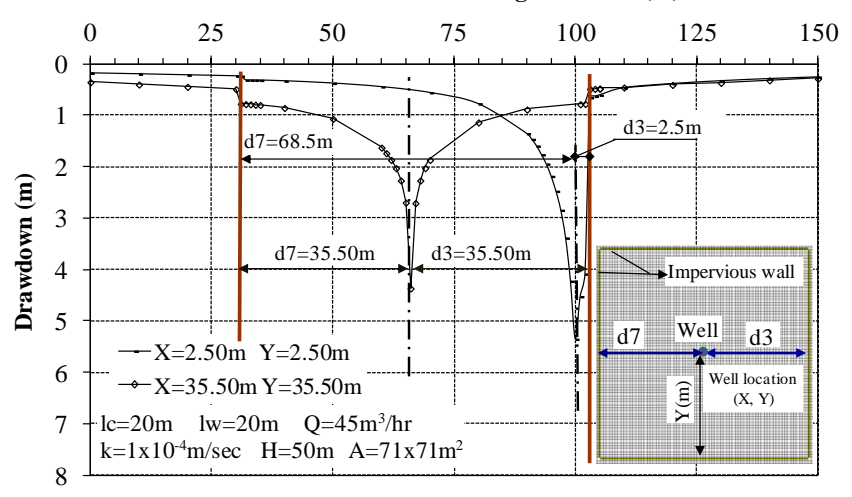

Figure 8. Drawdown curve for different well location in A $71 \times 71 \mathrm{~m} 2$

The following sets of Figures show comparisons of draw down curves for a well located at three different locations in a certain construction pit. Draw down curves along directions d7 and d3 (Figure 3), are shown in Figures 9 and 10, respectively, for a well located at three different locations in construction pit that is $21 \mathrm{~m} \times 21 \mathrm{~m}$ in size. The locations of the well are near wall corner edges at $X=2.5 \mathrm{~m}$ and $\mathrm{Y}=2.5 \mathrm{~m}$, center of the construction pit at $\mathrm{X}=10.5 \mathrm{~m}$ and $Y=10.5 \mathrm{~m}$, and midway between the two locations at $\mathrm{X}=6.5 \mathrm{~m}$ and $\mathrm{Y}=6.5 \mathrm{~m}$. Similarly, the pairs of Figures $11 \& 12,13 \& 14$, and $15 \& 16$, show the drawdown curves comparisons in construction pits $31 \times 31 \mathrm{~m}, 41 \times 41 \mathrm{~m}$ and $71 \times 71 \mathrm{~m}$, respectively.

In those Figures, it can be observed that as well location moves away from near the impervious wall toward the center of the construction pit, the drawdown of the well decreases. In general for different distances from well center, it can be shown that as distance of point where required to predict drawdown measured from well center increases, drawdown decreases (Mohamed et al. 2013). The closer he the well locations to the impervious wall, the greater is the drawdown. This is more pronounced as the size of the construction pit decreases. Further, the drawdown decreases as the construction pit size increases. It is expected that the observed tend may change if the ratio of well penetration to wall penetration changes (Mohamed et al., 2013).

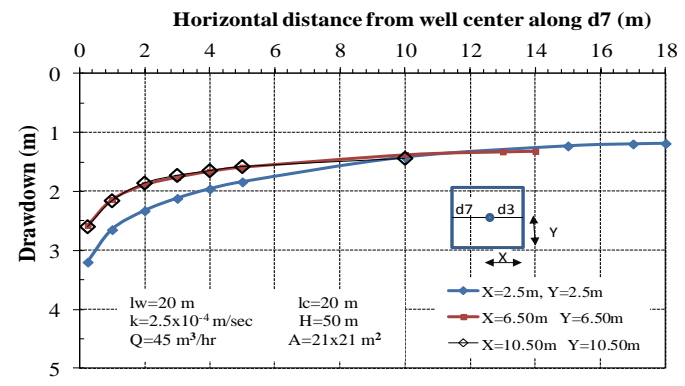

Figure 9. Drawdown results along d7 for different well locations for $\mathrm{W} 21 \mathrm{~m}$

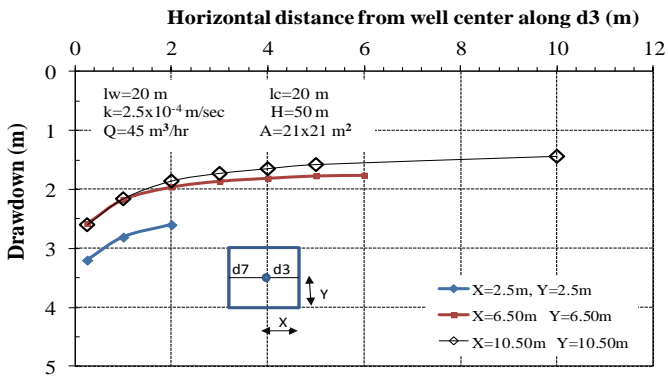

Figure 10. Drawdown results along d3 for different well locations for W $21 \mathrm{~m}$ 


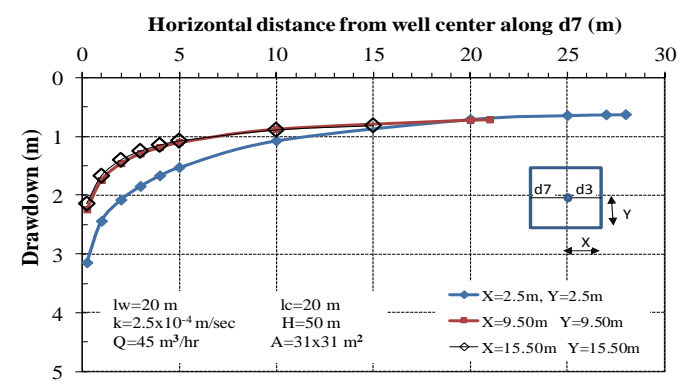

Figure 11. Drawdown results along $\mathrm{d} 7$ for different well locations for W $31 \mathrm{~m}$

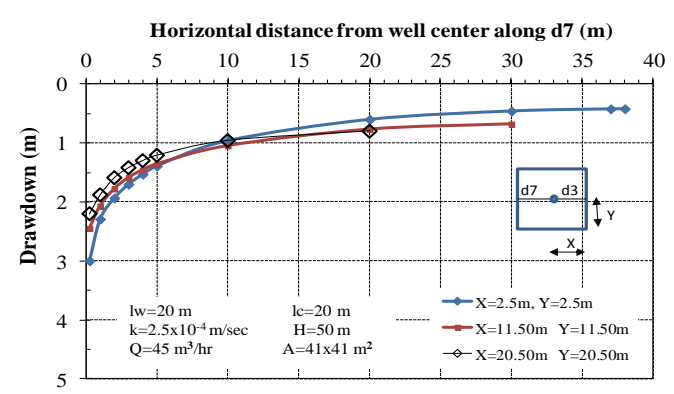

Figure 5. Drawdown results along $\mathrm{d} 7$ for different well locations for W $41 \mathrm{~m}$

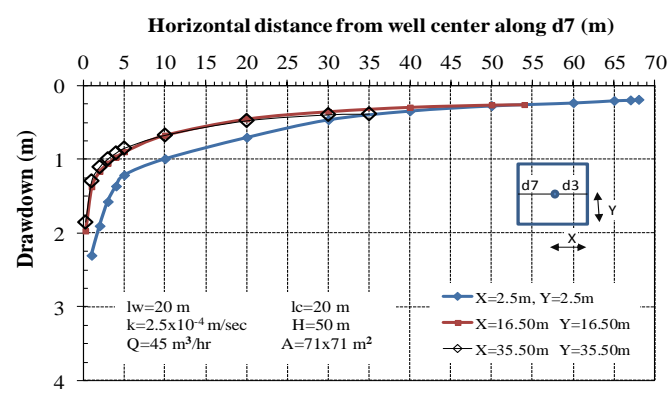

Figure 15. Drawdown results along d7 for different well locations for W $71 \mathrm{~m}$

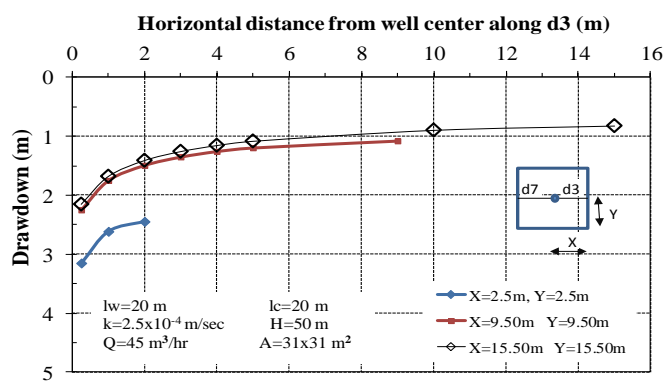

Figure 4. Drawdown results along d3 for different well locations for W $31 \mathrm{~m}$

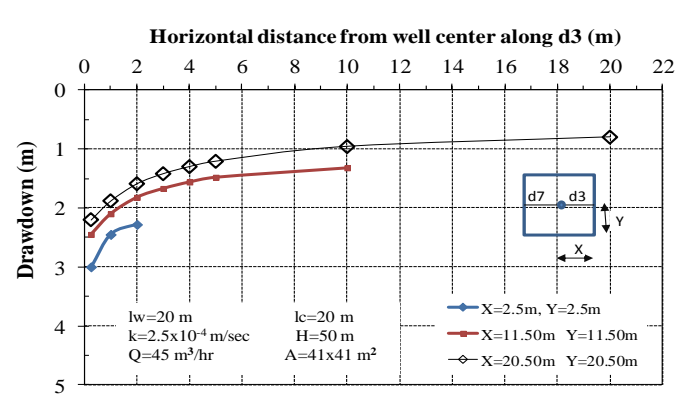

Figure 6. Drawdown results along d3 for different well locations for W $41 \mathrm{~m}$

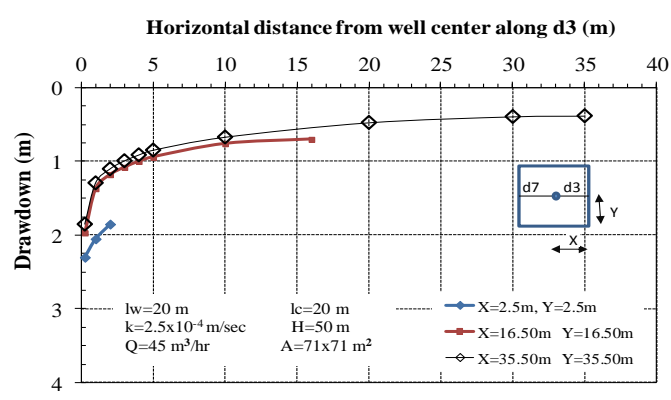

Figure 16. Drawdown results along d3 for different well locations for $\mathrm{W} 71 \mathrm{~m}$

\subsection{Draw down curves at different directions}

Figures 17 shows the draw down curves in all directions for a well located near the edge corner of construction pit with a size $21 \times 21 \mathrm{~m}$. Similarly, Figure 18 shows draw down curves for a well at edge corner of construction pit with the size of $71 \times 71 \mathrm{~m}$. It can be observed that drawdown at near distance from wall edge (where D about $3.53 \mathrm{~m}$ ) is higher than that obtained at the same distance from well center in the long directions (where D between $18.5 \mathrm{~m}$ and $68.5 \mathrm{~m})$. 


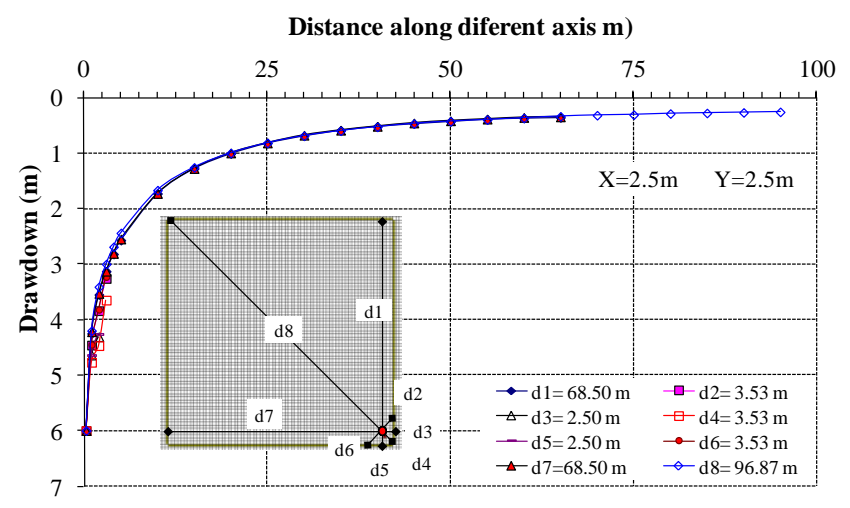

Figure 18. Drawdown results in different directions for $\mathrm{W}$ of $71 \mathrm{~m}(\mathrm{X}=2.5 \mathrm{~m}$,

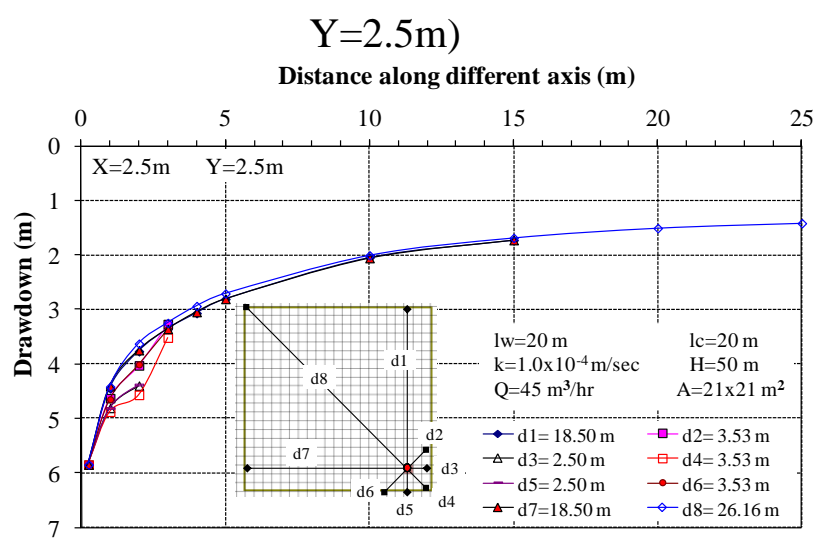

Figure 17. Drawdown results in different directions for $\mathrm{W}$ of $21 \mathrm{~m}(\mathrm{X}=2.5 \mathrm{~m}$,

$$
\mathrm{Y}=2.5 \mathrm{~m} \text { ) }
$$

Figures 19 and 20 show the drawdown curves in all directions for a well located at the center of construction pits with sizes $21 \times 21 \mathrm{~m}$ and $71 \times 71 \mathrm{~m}$, respectively. It can be concluded that drawdown at different directions are nearly equal for both areas $21 \times 21 \mathrm{~m}$ and $71 \times 71 \mathrm{~m}$.

Distance along different axis (m)

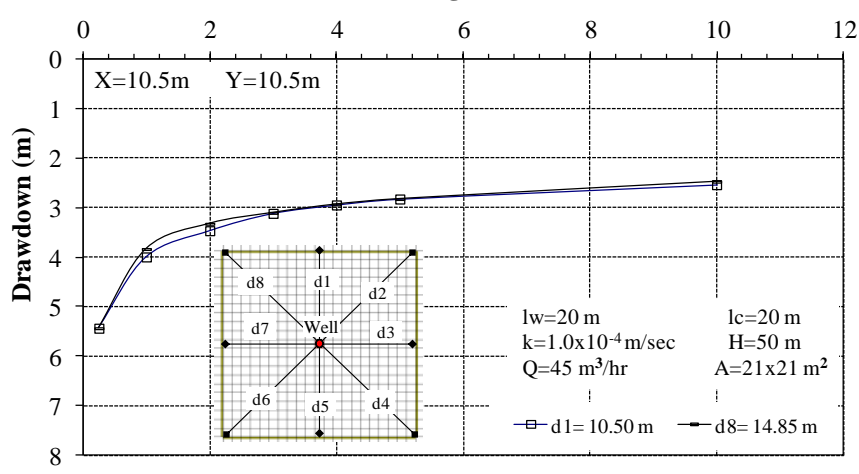

Figure 19. Drawdown results in different directions for $\mathrm{W}$ of $21 \mathrm{~m}(\mathrm{X}=10.5 \mathrm{~m}$,

$$
\mathrm{Y}=10.5 \mathrm{~m})
$$




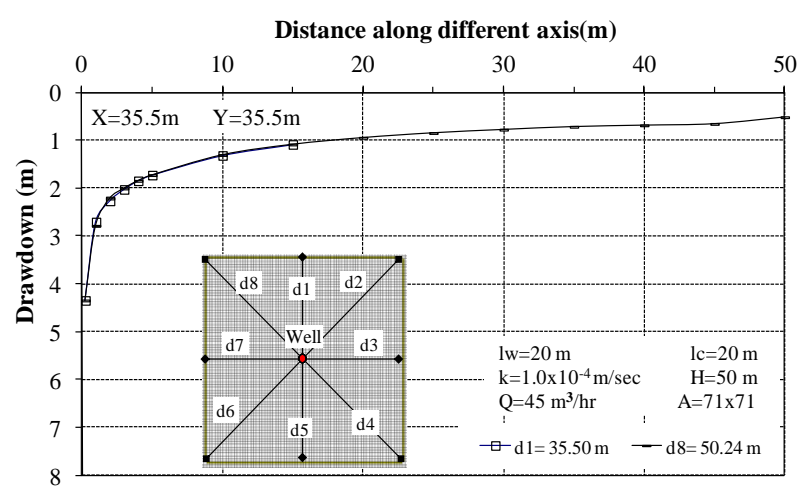

Figure 20. Drawdown results in different directions for $\mathrm{W}$ of $71 \mathrm{~m}(\mathrm{X}=35.5 \mathrm{~m}$,

$$
\mathrm{Y}=35.5 \mathrm{~m})
$$

\subsection{Draw down at well center}

Figure 21 shows the relationship between drawdown at or near well center versus distance between well center and wall edge in construction pit with various sizes. In general, as the distance between well center to impervious wall edge increases, the drawdown at or near the center of the well decreases. The values of the drawdown decrease with the increase in construction pit size. Further, the variation of the drawdown with distance, decreases with the increase in the size of the construction pit. It is expected that the observed tend may change if the ratio of well penetration to wall penetration changes (Mohamed et al., 2013).

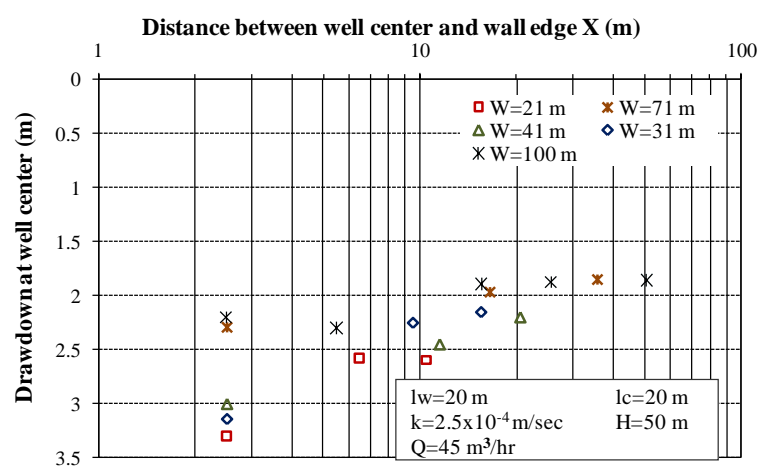

Figure 21 Drawdown at well center versus distance between well center and impervious wall.

\subsection{Sudden change in drawdown across impervious boundary}

As described earlier in Figure 3, sudden change in drawdown is the difference between drawdown just before and after the impervious wall along a drawdown curve when crossing the impervious wall. Figure 21 shows the relationship between sudden change in drawdown across impervious wall versus distance between well center and wall edge in construction pit with various sizes. The closer is the well from the impervious wall; the larger is the sudden change in drawdown across the impervious boundary. The sudden change in drawdown increases as the size of the construction pit decreases. It is expected that the observed tend may change if the ratio of well penetration to wall penetration changes (Mohamed et al., 2013). 


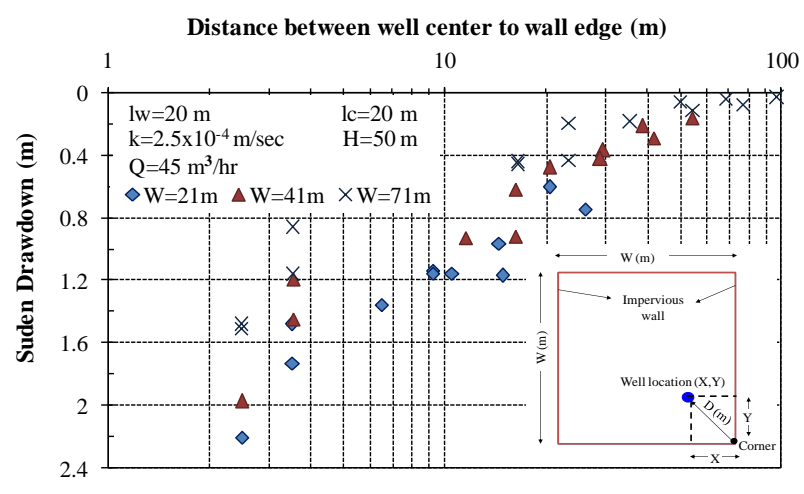

Figure 22 Sudden change in drawdown across impervious wall versus distance to wall edge

\section{Conclusion and Concluding Remarks}

This paper focuses on dewatering systems that comprise with partially penetrating deep wells inside square areas enclosed by impervious walls partially penetrating unconfined aquifers. There are many factors that may influence the drawdown of a well in such dewatering system. A comprehensive parametric analysis was carried out to investigate the influence of all the parameters on the drawdown of a deep well in a dewatering system. This paper focuses on the influence of well location on the drawdown a single well.

Generally, the drawdown results depend on well location as compared to the impervious wall. As well gets closer to the impervious wall edge, drawdown increases.

As the distance between well center to impervious wall edge increases; the drawdown at or near the center of the well decreases.

Drawdown around a well in the short directions toward impervious wall is greater than that in the long directions.

The closer is the well from the impervious wall; the larger is the sudden change in drawdown across the impervious boundary.

The construction pit size has significant influence on the amounts of drawdown in general. As the size of the construction pit increases, the drawdown decreases.

It is expected that the observed tend may change if the ratio of well penetration to wall penetration changes (Mohamed et al., 2013).

\section{References}

Abdel Haleem, A. (2006). Study of Deep Wells Dewatering System Enclosed by Partially Penetrating Cutoff Walls in Unconfined Aquifer, M.Sc. Thesis, Civil Engineering, Public Works Department, Cairo University, Egypt.

Harbaugh, A. W., Banta, E. R., Hill, M. C., and McDonald, M. G. (2000), "MODFLOW2000, The U.S. Geological Survey Modular Groundwater Model User Guide to Modularization Concepts and The Groundwater Flow Process".

Mohamed, D. R. (2012). Effect of well depth and depth of surrounding impervious wall on drawdown of ground water control system in an unconfined aquifer. M.Sc. Thesis, Civil Engineering, Public Works Department, Cairo University, Egypt.

Mohamed, D. R., Shahien, M. M. and Hafez, H. H. (2013). "Influence of Well Location on Drawdown in Area Surrounded by Vertical Partially Penetrating Cutoff Walls", Proceedings of the $18^{\text {th }}$ Int. Conference on Soil Mechanics and Geotechnical Engineering, Paris (Submitted) 
Driscoll, F. G., (1986). Groundwater and Wells, 2nd ed., Johnson Screens, Wheelabrator Water Technologies Inc., St. Paul, MN.

Freeze, R. A. and Cherry, J. A. (1979), Groundwater, Prentice-Hall, Inc.

McDonald M.G. and Harbaugh A.W. (1988). "A Modular Three-Dimensional Finite Difference Ground-Water Flow Model”, U.S. Geological Survey Open-File Report 83-875.

Powers, J.P. “Construction Dewatering”, Second Edition, J. Willy and Sons, 1992.

Preene M., Roberts T.O.L, Powrie W., and Dyer M.R., "Groundwater Control - Design and Practice", CIRIA Report No. C515, 2000.

NAVFAC, "Naval Facilities Engineering Command" Dewatering and Groundwater Control (NAVFAC P-418; TM 5-818-5 / AFM 88-5, Chapter 6), November, 1983. 